\title{
An Explanation of Each-Way Wagers in Three Models Of Risky Choice
}

\author{
D. A. Peel University of Lancaster
}

Corresponding author. E-mail address: d.peel@lancaster.ac.uk

\section{Tel 0152465201 Lancaster University Management School, Lancaster, LA1 4YX United Kingdom.}

\begin{abstract}
Punters may engage in betting on both a selection in an event to finish first or in one of the number of places, e.g. $2^{\text {nd }}, 3^{\text {rd }}$ or $4^{\text {th }}$ If the selection wins both the win and place (or show) parts of the wager will pay out. If the selection places (or shows) you lose the stake on win part of the wager but receive a pay-out on the place or show part of the wager. When the amounts staked with bookmakers at fixed odds on the win and place are equal it is called an each-way bet. Eachway bets are apparently popular with punters but inconsistent with prominent models of wagering which assume gamblers are everywhere risk-seeking. In this note we derive for the first time the conditions for win and place bets to be optimal in these three models of risky-choice and illustrate with numerical examples. The mathematical conditions for the each-way wager to be optimal, as opposed to a win and place wager with different stakes, are complicated and appear likely to occur rarely in practice. However bettors obviously see the attraction in giving themselves two ways to bet on the one horse, or two ways to win and betting each-way. From this perspective we suggest part of the "each way" betting attraction is that they are quick and easy to compute -a heuristic- to solve an otherwise complex betting strategy.
\end{abstract}

Keywords: Each-Way bets, Cumulative Prospect Theory, Rank Dependent Utility, JEL classification: C72; C92; D80; D84 
An Explanation of Each-way Wagers in Three Models of Risky Choice

\section{Introduction}

Punters may engage in betting on both a selection in an event to finish first or in one of the number of places, e.g. $2^{\text {nd }}, 3^{\text {rd }}$ or $4^{\text {th }}$. If the selection wins both the win and place (or show $)^{1}$ parts of the bet will pay out. If the selection places or shows, e.g. $2^{\text {nd }}, 3^{\text {rd }}$ or $4^{\text {th }}$, you lose the stake on win part of the bet but get paid out on the place or show part. When the win and place stakes are equal and the bet is placed with a bookmaker the wager is called an each-way bet. The place odds in an each-way bet are a quarter or a fifth of the win odds dependent upon the number of runners in the race and its type ${ }^{2}$. Each-way bets

${ }^{1}$ In the US, a pari-mutuel wagering system, if you wager to place your horse must finish first or second for you to collect. If you wager to show, your horse must finish first, second, or third. In both cases you only collect the place or show payoff.

${ }^{2}$ Each-way terms for horse (and greyhound racing events) by bookmakers in the UK, Australia and Ireland are settled on the actual number of runners that are deemed to have run in the race. The odds are for handicaps of more than 16 runners - 1/4 odds on first four places. Handicaps of 12-15 runners - 1/4 odds on first three places. All other races of more than 8 runners - 1/5 odds on first three places. All races of 5-7 runners - 1/4 odds on the first two places. All races of less than 5 runners - place money goes on to win. 
are apparently popular with punters according to Betfair and Internet postings ${ }^{3}$. This popularity accords with some early evidence of Johnson and Bruce (1998) based on a random sample of 1211 bets made with bookmakers in the UK. They reported that 349 or $28.8 \%$ of the sample of bets were each-way bets. More recently Gainsbury and Russel (2015) describe the results of an analysis of 2,522,299 bets placed with an Australian online wagering operator over a 1-year period. Of the bets placed on horses (or greyhounds) there were 990814 win bets, 398767 each-way bet and 211469 place bets. Consequently of the total number of bets on horses $24.9 \%$ were each-way bets.

Each-way bets offer punters a diversified wagering strategy. This popular wagering strategy is therefore inconsistent with a still prominent model of wagering that assumes the representative bettor exhibits everywhere risk-seeking preferences, (e.g. Weitzman (1965) and Quandt (1986)). In order to offer an explanation of the popularity of eachway bets at actuarially unfair odds based on risky choice models it is therefore necessary to consider models in which individuals utility or value functions are assumed to exhibit risk-aversion. The non-expected utility models Rank Dependent Utility (RDU) of Quiggin (1993) and Cumulative Prospect Theory (CPT) of Tversky and Kahneman (1992) exhibit this property. In RDU an individual's utility function is assumed everywhere risk-averse and in CPT an individual's value function over gains is assumed everywhere risk-averse. In both of these models it is assumed that the representative agent's subjective probabilities of an outcome differ from the objective probabilities via inverted s-shaped probability weighting functions. As a consequence a horse can exhibit

${ }^{3}$ E.g. https://betting.betfair.com/each-way-betting-calculator.html, http://www.bettingexpert.com/how-to/bet-each-way-horse-racing 
positive subjective expected returns and the representative punter can obtain positive expected value or expected utility from wagering on the horse to win in a race even though the odds are actuarially fair ${ }^{4}$. Given RDU and CPT can explain wagering on a horse to win at actuarially unfair odds we investigate for the first time the conditions for win and place or each-way bets to exhibit greater expected utility or value than the optimal single wager in these models.

We also consider the optimality of win and place wagers in standard expected utility with an every-where concave utility function. As is well known expected utility maximizers (EU) with an everywhere concave utility function defined over betting wealth will not wager at actuarially unfair odds. However professional gamblers, perhaps insiders, who might perceive a positive expected return to a unit bet, are often stated to employ the famous single Kelly wager (1956) which is derived for EU preferences assuming logarithmic utility ${ }^{5}$. The Kelly wager is also often employed to test models of efficiency in gambling markets. (See e.g. Lessman et al (2009)). Given these points it appears of interest to derive the optimal "Kelly" each-way wagers and compare it with

${ }^{4}$ It is interesting to note that Jullien and Salanié (2000), Snowberg and Walters (2010) and Fess et al (2016) report that CPT provides a parsimonious fit to horse racing data employing bookmaker data on single bets in horse races which exhibits the favorite long shot bias. The favorite-long shot is a prominent feature of horse racing data where betting odds provide biased estimates of the probability of a horse wining and long shots are over-bet whereas favorites are under bet

5 E.g. https://www.pinnacle.com/en/betting-articles/betting-strategy/how-to-use-kellycriterion-for-betting 
the optimal single Kelly wager. Standard EU is also a special case of RDU when probability distortion is assumed absent.

Kelly wagers are based on logarithmic utility and for this reason we also employ logarithmic utility or value functions when analysing RDU and CPT. However our results are qualitatively the same with other specifications of the value or utility functions.

Our analysis is new and demonstrates that win and place or each-way wagers can be an optimal wagering strategy. However we find that the formal conditions for an each-way wager to be optimal, as opposed to a win and place wager with different stakes, are very complicated and appear unlikely to occur in practice except by chance.

One feature of win and place wagers is that punters have to form a subjective probability of the place probability. This is a complicated process even for researchers in the area of testing market efficiency in gambling markets. The widely employed Harville place probabilities are based on formulae employing the win probabilities of each horse in the race. (See e.g. Harville (1973). Stern (1987) develops alternative formulae employing running times based on gamma distributions. Lo and Bacon-Shone (1994) demonstrated that the Stern model provided a better fit than the Harville model for particular racing data but not in general. These formal mathematical methods of computing the place probability we presume will not in general be employed by the typical punter. However as documented above each-way bets are popular with punters. Bettors obviously see attraction in giving themselves two ways to bet on the one horse, or two ways to win. From this perspective perhaps a part of the "each way" betting attraction is that they are quick and easy to compute -a heuristic- a rule of thumb to solve an otherwise complex betting strategy. 
The structure of the rest of the note is set out as follows. In section one we examine the optimal win and win and place stakes in standard expected utility. We then examine the same issue assuming RDU in section two and CPT in section three. The final section is a brief conclusion.

\section{Section 1 Expected Utility and Win and Place Bets}

With the assumption of log utility and betting wealth of one the expected utility, EU, of a single wager with bet size, $\mathrm{j}$, of an expected utility maximiser is given by

$$
E U=p \ln (1+j a)+(1-p) \ln (1-j)
$$

Where $\mathrm{p}$ is the objective win probability and a is the winning odds.

Maximum expected utility is obtained from (1) when stake size is given by

$$
\mathrm{j}=\frac{\mathrm{pa}-(1-\mathrm{p})}{\mathrm{a}}=\frac{\mu}{\mathrm{a}}
$$

where $\mu=$ pa $-(1-p)$ is the expected return to a unit stake.

The optimal stake, $\mathrm{j}$, in (2) is the famous Kelly stake.

The expected utility of a win and place bet for an expected utility maximiser with logarithmic utility and betting wealth of one is given by

$$
E U=p \ln (1+s a+v b)+q \ln (1+v b-s)+(1-p-q) \ln (1-s-v)
$$

Where $\mathrm{p}$ is the probability of coming first, $\mathrm{q}$ is the probability of coming $2^{\text {nd }}, 3^{\text {rd }}$ or $4^{\text {th }}$. The winning odds are a, the place odds $b, s$ is the win stake and $v$ the place stake. ${ }^{6}$

${ }^{6} \mathrm{We}$ assume for simplicity that the place odds are fixed at a constant value of $\mathrm{b}$. However if the optimal place wager, $\mathrm{v}$, is greater than the optimal win wager, $\mathrm{s}$, in practice the 
From the first order conditions for a maximum we derive that optimal stakes are given by

$\mathrm{s}=\frac{\mu-\lambda}{\mathrm{a}-\mathrm{b}}$

$\mathrm{v}=\frac{\lambda \mathrm{a}-\mu \mathrm{b}}{\mathrm{b}(\mathrm{a}-\mathrm{b})}$

Where $\mu=\mathrm{pa}-(1-\mathrm{p})$ and $\lambda=(\mathrm{p}+\mathrm{q}) \mathrm{b}-(1-\mathrm{p}-\mathrm{q})$ are respectively the expected returns to a single unit stake win bet and the expected return to a single unit stake place bet. If $v>0$ and $s>0$ the second order condition for a maximum are met.

From 4(a) and 4(b) we observe that it is not optimal to have a win and place bet unless the expected return to a unit stake single win bet, $\mu$, is greater than the expected return to a unit single place bet, $\lambda$. In addition the expected return to unit stake of the place wager has to be positive and large enough so that $\lambda \mathrm{a}>\mu \mathrm{b}$.

When these two conditions are met there are three possibilities. When $\mathrm{s}>\mathrm{v}$ the punter will engage in a single win bet of size $\mathrm{s}-\mathrm{v}$ and an each-way bet of size $\mathrm{v}$. When $\mathrm{s}=\mathrm{v}$ the punter will have an each-way bet of size s. When $v>s$ the punter would have an each-way bet with stake size s and a place bet of size v-s. We note that a win and place wager has a smaller expected return per unit staked than a win wager.

It is interesting to examine the implications for relative stake sizes of the optimal each way wager and the optimal single win wager.

odds are likely to be marginally less than $\mathrm{b}$ for the bet component, v-s. Allowing for this complication implies optimal solutions for $\mathrm{s}$ and $\mathrm{v}$ that are very close to those given in the formulae in the paper though the formula is too long to include in the text. 
When the stake $s=v$ from $4(a)$ and $4(b)$ we obtain

$$
\lambda=2 \mu \frac{\mathrm{b}}{\mathrm{b}+\mathrm{a}}
$$

Since we can define $\mathrm{b}=\frac{\mathrm{a}}{\mathrm{n}}$, where $\mathrm{n}$ is the place proportion of the odds, we obtain employing (5) that the optimal stakes in the each-way wager are given by

$$
\mathrm{s}=\mathrm{v}=\frac{\mu \mathrm{n}}{\mathrm{a}(1+\mathrm{n})} \quad \mathrm{n}=4 \text { or } 5
$$

Consequently the total stake on the each-way bet with a bookmaker is

$$
\mathrm{s}+\mathrm{v}=\frac{2 \mu \mathrm{n}}{\mathrm{a}(1+\mathrm{n})} \quad \mathrm{n}=4 \text { or } 5
$$

It follows from (2) and (6) that the optimal "Kelly" each-way wager has a win component that is $4 / 5$ or $5 / 6$ of the optimal single "Kelly" wager. However from (2) and (7) the total stake of the each-way wager, s+v, is 1.6 or 1.67 times greater than the optimal single wager, $\mathrm{j}$.

As an example consider the case where a horse has odds of winning of $a=33 / 1$ with a win probability of $\mathrm{p}=3.2353\left(10^{-2}\right)$. This implies an expected return per unit staked of $\mu=0.1$. The place probability $q=8.0079(10)^{-2}$ and the place odds $b=33 / 4$. This implies an expected return to a single place bet of $\lambda=0.04$. The optimal win, $s$, and place stake, $\mathrm{v}$, are both $2.4242\left(10^{-3}\right)$. The optimal single win stake is $\mathrm{j}=3.0303\left(10^{-3}\right)$. Consequently the total stake in the each-way bet is 1.6 times greater than the optimal single wager. The expected utility of the each- way wager is $1.6497\left(10^{-4}\right)$ and the expected utility of the optimal single wager is $1.4685\left(10^{-4}\right)$. Consequently in this example the expected utility of the optimal each-way bet is 1.123 times greater than the optimal single wager. 


\section{Section 2 Rank Dependent Utility and Win and Place Bets}

In RDU of Quiggin (1993) individuals utility functions are assumed to have the same properties as in EU and are assumed everywhere risk-averse over betting wealth.

In contrast to EU the objective probabilities of outcomes are replaced by subjective probabilities. It is assumed in RDU that the representative agent's subjective probabilities of an outcome differ from the objective probabilities via an inverted s-shaped probability weighting functions. Quiggin assumed that subjective probabilities are greater (less) than objective probabilities when the objective probabilities are less (greater) than 0.5. Quiggin also assumed a cumulative weighting process (as subsequently assumed by Tversky and Kahneman (1992)) from which the subjective probabilities, or decision weights, associated with each of the outcomes in a lottery are derived. In the cumulative process Quiggin assumed the worst outcome is weighted first ${ }^{7}$. The subjective probability distortion can imply subjective positive expected returns to single bets on long shots and therefore positive expected utility to a single win bet ${ }^{8}$.

To illustrate the implications of RDU for a win and place or each-way wagers we assume logarithmic utility so that in the absence of probability distortion our results will simplify to the results obtained in section one for the standard expected utility maximiser. For simplicity we retain the same definitions of variables as in section one. Assuming betting wealth of one expected utility for a single optimal wager is given by

\footnotetext{
${ }^{7}$ This differs from CPT where outcomes are weighted from best to worst.

${ }^{8}$ Recent research by Harrison and Swarthout (2016) also demonstrates that RDU can better explain some experimental data than CPT.
} 


$$
E U=w(1-p) \ln (1+j a)+[1-w(1-p)] \ln (1-j)
$$

Where $w(1-p)$ is the probability weighting function.

The optimal stake is given by

$$
\mathrm{j}=\frac{[1-w(1-p)] a-w(1-p)}{a}=\frac{\mu^{s}}{a}
$$

Where $\mu^{\mathrm{s}}=[1-\mathrm{w}(1-\mathrm{p})] \mathrm{a}-\mathrm{w}(1-\mathrm{p})$ is the subjective return to a unit stake win bet.

Assuming betting wealth of one the expected utility of a win and place bet is given by

$$
\begin{aligned}
E U=w(1-p-q) \ln (1-s-v)+[w(1-p)- & w(1-p-q)] \ln (1+v b-s) \\
+ & +1-w(1-p)] \ln (1+s a+v b)
\end{aligned}
$$

Where $\mathrm{w}(1-\mathrm{p}-\mathrm{q})$ and $\mathrm{w}(1-\mathrm{p})$ are probability weighting functions and the probability weights are given by the cumulative weighting process assumed by Quiggin (1982). Other variables are defined as in EU for ease of interpretation.

From the first order conditions for a maximum we derive that the optimal stakes for the win and place bet in RDU are given by

$$
\begin{gathered}
\mathrm{s}=\frac{\mu^{\mathrm{s}}-\lambda^{\mathrm{s}}}{\mathrm{a}-\mathrm{b}} \\
\mathrm{v}=\frac{\lambda^{\mathrm{s}} \mathrm{a}-\mu^{\mathrm{s}} \mathrm{b}}{\mathrm{b}(\mathrm{a}-\mathrm{b})}
\end{gathered}
$$

where $\mu^{\mathrm{s}}=[1-\mathrm{w}(1-\mathrm{p})] \mathrm{a}-\mathrm{w}(1-\mathrm{p})$ is the subjective expected return to a unit stake on a win bet and $\lambda^{s}=[1-\mathrm{w}(1-\mathrm{p}-\mathrm{q})] \mathrm{b}-\mathrm{w}(1-\mathrm{p}-\mathrm{q})$ is the subjective expected return to a 
unit stake on a place only wager. We observe from (11a) and (11b) that in the absence of probability distortion the optimal stakes are the same as for the standard expected utility maximiser with logarithmic utility given in 4(a) and 4(b). ${ }^{\mathrm{i}}$

We now provide an example to illustrate that the RDU agent can optimally wager eachway when the winning odds for horses exhibit a favorite long-shot bias. A favorite longshot bias implies long shots have much lower expected returns to a unit stake than more favored horses. (See e.g. Sauer (1998)).

We assume the probability weighting functions take the functional form suggested by Prelec (1998).

These are $\mathrm{w}(1-\mathrm{p})=\mathrm{e}^{-\sigma(-\ln (1-\mathrm{p}))^{\phi}}, \mathrm{w}(1-\mathrm{p}-\mathrm{q})=\mathrm{e}^{-\sigma(-\ln (1-\mathrm{p}-\mathrm{q}))^{\phi}}$

We assume that $\sigma=0.95$ and $\phi=0.860051$. These parameter values imply over (under) weighting of probabilities less (greater) than 0.5 but no probability distortion when the objective probability is equal to 0.5 as assumed by Quiggin (1982).

To illustrate that the individual with RDU preferences can engage in each-way betting when the bookmaker odds exhibit a favorite-long shot bias we assume the relationship between the objective probability and the odds in the race horse market is well approximated by the relationship

$\mathrm{p}=\frac{1}{(1+\mathrm{a})^{\alpha}}$ with $\alpha>1$ 
We assume that $\alpha=1.12$ typical of the estimates obtained in the relationship between the expected rate of return per unit staked and the win probability reported in empirical work on the favorite long-shot bias. (See e.g. Golec and Tomarkin (1998)). ${ }^{9}$

With these assumptions maximum expected utility is obtained from a single bet by wagering on a 33/1 long shot. The objective win probability, $\mathrm{p}$, is equal to $1.9264\left(10^{-2}\right)$ and the subjective win probability is equal to $3.1564\left(10^{-2}\right)$. The objective expected return to a unit stake win bet on this horse is -0.34503 and the subjective expected return to a single unit stake win bet is $7.3189\left(10^{-2}\right)$. The optimal stake on the single wager is $\mathrm{j}=$ $2.2179\left(10^{-3}\right)$ with expected utility of $7.9309\left(10^{-5}\right)$.

The objective probability of the horse placing is $\mathrm{q}=8.6883\left(10^{-2}\right)$ with a subjective probability of placing $(w(1-p)-w(1-p-q))=0.10322$. The place odds are $33 / 4$ implying an objective expected return to a unit place bet of -0.19328 and a subjective expected return to a unit place bet of $2.4399\left(10^{-2}\right)$. Employing 11(a) and 11(b) the optimal win and place stakes are equal with $\mathrm{s}=1.8481\left(10^{-3}\right)$ and $\mathrm{v}=1.8481\left(10^{-3}\right)$. This wager has an expected utility of $8.8319\left(10^{-5}\right)$. Consequently the expected utility of optimal each way wager is 1.136 times greater than the optimal single wager.

${ }^{9}$ The relationship between the expected rate of return and the win probability in empirical work typically is well approximated by the relationship $(1+\mu)=p^{1-\frac{1}{\alpha}}$ with $\alpha$ around 1.12. Since $p \equiv \frac{1+\mu}{1+a}$ by substitution we obtain $p=\frac{1}{(1+a)^{\alpha}}$. (See e.g.Golec and Tomarkin (1998) and Sauer (1998)). 


\section{Section 3 Cumulative Prospect Theory and Win and Place Bets}

Cumulative Prospect Theory of Tversky and Kahneman (1992) is widely regarded as the major alternative to expected utility theory in explaining risky choice. In CPT it is assumed that from a reference point the representative agent is solely risk-averse over gains and solely risk-seeking over losses. The representative individual is also assumed to be loss-averse so that losses reduce utility (called expected value in CPT) by more than gains of the same amount. As in RDU it is assumed that the representative agent's subjective probability of an outcome differs from the objective via an inverted s-shaped probability weighting function. Small probabilities are assumed over weighted and larger ones under weighted. The cumulative weighting process is the same as assumed in RDU except the best outcome is weighted first. It is also assumed that the probability weighting function over losses exhibits a smaller degree of probability distortion than the probability weighting function over gains. As with RDU the probability distortion can result in positive subjective expected returns to single win wagers even though the objective expected return are negative.

For a single wager expected value, EV, in CPT is given by

$$
E V=w^{+}(p) U(G)-w^{-}(1-p) U(L)
$$

Where $\mathrm{U}(\mathrm{G})$ is the value function over gains, $\mathrm{U}(\mathrm{L})$ the value function over losses $\mathrm{w}^{+}(\mathrm{p})$ is the probability weighting function over gains and $\mathrm{w}^{-}(1-\mathrm{p})$ the probability weighting function over loses.

To illustrate that a CPT can obtain higher expected value from a win and place wager than a single optimal wager we employ logarithmic value functions recently reported by Scholten and Read (2014) to provide a parsimonious fit to experimental data. It is also a 
consistent choice given we employed logarithmic specifications of the utility function in the examples in sections 1 and 2 .

Employing log value functions expected value, $\mathrm{EV}$, for the single wager is given by

$\mathrm{EV}=\mathrm{w}^{+}(\mathrm{p}) \ln (1+\mathrm{r} \rho \mathrm{ja})-\mathrm{w}^{-}(1-\mathrm{p}) \mathrm{k} \ln (1+\rho \mathrm{j})$

Where $\mathrm{w}^{+}(\mathrm{p}), \mathrm{w}^{-}(1-\mathrm{p})$ are the probability weighting functions over gains and losses, $\mathrm{j}$ is the stake and $\mathrm{r}, \mathrm{k}$ and $\rho$ are positive constants.

The optimal stake for the single wager is derived from (13) as

$$
\mathrm{j}=\frac{\mathrm{w}^{+}(\mathrm{p}) \mathrm{ra}-\mathrm{w}^{-}(1-\mathrm{p}) \mathrm{k}}{\mathrm{r} \rho \mathrm{a}\left[\left(\mathrm{w}^{-}(1-\mathrm{p}) \mathrm{k}-\mathrm{w}^{+}(\mathrm{p})\right]\right.}
$$

The expected value of a win and place wager is given by

$\mathrm{EV}=\mathrm{w} \ln [1+\mathrm{r} \rho(\mathrm{sa}+\mathrm{vb})]+(\mathrm{g}-\mathrm{w}) \ln [1+\mathrm{r} \rho(\mathrm{vb}-\mathrm{s})]-\mathrm{zk} \ln [1+\rho(\mathrm{s}+\mathrm{v})]$

Where $\mathrm{w}=\mathrm{w}^{+}(\mathrm{p}), \mathrm{g}=\mathrm{w}^{+}(\mathrm{p}+\mathrm{q}), \mathrm{z}=\mathrm{w}^{-}(1-\mathrm{p}-\mathrm{q})$ are the probability weighting functions with the decision weights given by the cumulative weighting process assumed by Tversky and Kahneman (1992). Other variables are defined as for RDU.

We note from (15) that the subjective expected return per unit staked to the win portion of the win and place wager, $\mu^{s}$, is given by $\mu^{s}=w(1+a)-g-z$, and the subjective return to a unit stake on the place component by $\lambda^{\mathrm{s}}$, by $\lambda^{\mathrm{s}}=\mathrm{gb}-\mathrm{z}$.

The expressions for the optimal stakes $s$ and $v$ derived from (15) are given by 


$$
\begin{aligned}
& \mathrm{s}=\frac{(\mathrm{rb}-1)[\mathrm{w}(1+\mathrm{a})-\mathrm{g}(1+\mathrm{b})]}{\mathrm{r} \rho(1+\mathrm{b})(\mathrm{a}-\mathrm{b})(\mathrm{kz}-\mathrm{g})}=\frac{(\mathrm{rb}-1)\left[\mu^{\mathrm{s}}-\lambda^{\mathrm{s}}\right]}{\mathrm{r} \rho(1+\mathrm{b})(\mathrm{a}-\mathrm{b})(\mathrm{kz}-\mathrm{g})} \\
& \mathrm{v}=\frac{(1+\mathrm{a})(\mathrm{rb}-1) \mathrm{wb}-(1+\mathrm{b})[\mathrm{gb}(\mathrm{ar}-1)-\mathrm{kz}(\mathrm{a}-\mathrm{b})]}{\mathrm{r} \rho \mathrm{b}(1+\mathrm{b})(\mathrm{a}-\mathrm{b})(\mathrm{kz}-\mathrm{g})}
\end{aligned}
$$

The optimal stakes have rather complicated formulae particularly for the place wager v. We also observe from (15), (16a) and (16b) that the parameter $\rho$ is a scaling constant. As we vary its value the optimal stake sizes varies but not the expected value of the wager. We assume that the probability weighting functions take the same functional form and parameter values as assumed by Tversky and Kahneman (1992). These are given by

$$
\begin{aligned}
& \mathrm{w}^{+}(\mathrm{p})=\frac{(\mathrm{p})^{\phi}}{\left[(\mathrm{p})^{\phi}+(1-\mathrm{p})^{\phi}\right]^{\frac{1}{\theta}}}, \mathrm{w}^{-}(1-\mathrm{p})=\frac{(1-\mathrm{p})^{\lambda}}{\left[\mathrm{p}^{\lambda}+(1-\mathrm{p})^{\lambda}\right]^{\frac{1}{\lambda}}}, \mathrm{g}=\mathrm{w}^{+}(\mathrm{p}+\mathrm{q})=\frac{(\mathrm{p}+\mathrm{q})^{\phi}}{\left[(\mathrm{p}+\mathrm{q})^{\phi}+(1-\mathrm{p}-\mathrm{q})^{\phi}\right]^{\frac{1}{\theta}}} \\
& \mathrm{z}=\mathrm{w}^{-}(1-\mathrm{p}-\mathrm{q})=\frac{(1-\mathrm{p}-\mathrm{q})^{\lambda}}{\left[(1-\mathrm{p}-\mathrm{q})^{\lambda}+(\mathrm{p}+\mathrm{q})^{\lambda}\right]^{\frac{1}{\lambda}}}
\end{aligned}
$$

with $\phi=0.61$ and $\lambda=0.69$.

Tversky and Kahneman (1992) define loss aversion as the ratio of the value of losses to the value of gains for symmetric losses and gains. For logarithmic value functions loss aversion has a lower bound of $\frac{\mathrm{k}}{\mathrm{r}}$ and an upper bound of $\mathrm{k}^{10}$. Tversky and Kahneman

${ }^{10}$ The ratio of the expected value of loss to gain for a symmetric amount, L, the definition of loss aversion of Tversky and Kahneman (1992) is given by $\frac{k \ln (1+\rho L)}{\ln (1+r \rho L)}$.The lower 
(1992) assumed a value of loss aversion of 2.25 . We set $k=2$ and $r=2$ which gives a value of loss aversion of approximately 1.0 for small stakes. This smaller value of loss aversion is more consistent with empirical estimates of loss aversion based on actual wagering data. (See e.g. Fees et al (2016) $)^{11}$.

We provide an example where the punter obtains maximum expected value from a single bet by wagering on a long shot with $a=33 / 1$. The objective win probability, $p$, is equal to $1.9264\left(10^{-2}\right)$ and the subjective win probability is equal to $3.1564\left(10^{-2}\right)^{12}$. The objective expected return to a unit stake win bet is -0.34503 and the subjective expected return to a single unit stake win bet is 1.7057 . We set the scaling factor $\rho=2.9476\left(10^{-2}\right)$ which implies an optimal stake of $\mathrm{j}=10$. This optimal single wager has a positive expected value of $3.2589\left(10^{-2}\right)$.

We now demonstrate that a win and place wager can exhibit greater expected value than the optimal single win wager. The win odds and probability of win are the same as assumed for the optimal single wager above. The place odds are $b=33 / 5$ and the objective place probability $q=0.085$ with a subjective place probability of 0.1655 . The objective expected return to a unit stake place bet is -0.2076 . From (17) we calculate that the optimal win stake in the win and place bet $s=10.83$ and the place stake $v=1.26$ which

bound of loss aversion is found by using L'Hopitals Rule as $\mathrm{L} \rightarrow 0$ loss aversion is given by $\frac{\mathrm{k}}{\mathrm{r}}$.

${ }^{11}$ We can provide examples of win and place wagering when the individual is lossaverse.

${ }^{12}$ These values are given from the same favorite-longshot bias employed in the RDU calculations. 
is nearly $20 \%$ higher than the optimal single stake. The win and place wager has expected value of $3.6149\left(10^{-2}\right)$ that is 1.10 times as large as the expected value of the optimal single wager.

The optimal conditions for the win and place stake given by (16a) and (16b) are extremely complex. It is interesting that an each-way bet of $\mathrm{s}=\mathrm{v}=8$ with the same parameter values has positive expected value of $3.2972\left(10^{-2}\right)$ which is greater than the optimal single wager. Although the expected value of the each-way wager is only marginally higher than the expected value of the optimal single wager it could be the heuristic choice of many punters given by the complexity of the optimal calculation.

\section{Conclusion}

Each-way bets are popular bets with punters but not explicable in models of risky choice where the utility functions of punters are assumed everywhere risk-seeking. In three prominent models of risky choice, EU, RDU and CPT the individual's utility or value function exhibit risk aversion. As a consequence individuals described by these models may engage in a diversified betting strategy and bet win and place or each-way. We provided for the first time some examples where win and place wagers had greater expected utility or expected value than an optimal single wager. In the case of RDU and CPT the each-way or win and place wagers can readily occur at actuarially unfair win odds.

The conditions for an each-way wager to be optimal at actuarially unfair odds appear unlikely to occur in practice except by chance. Both CPT and RDU are descriptors of real decision-makers. The attraction of each-way bets maybe that they are quick and easy to 
compute $-\mathrm{a}$ heuristic- to solve an otherwise complex betting strategy ${ }^{13}$. From the bookmakers perspective they also increase total stake size.

It was also suggested to me that there may be other good analogies to each-way bets in other subject areas where-by you win in case 1 or case 2. A medical example was suggested with two "winning" outcomes either "alive after 5 years" (a "win") or "alive after at least 1 year" (a "place"). These two outcomes have different odds and values since hospitals make bets when they spend $£ x$ on the patient hoping for one of the two outcomes above (which have pound values in terms of "value of human life" type calculations). The treatment cost and the "outcome values" imply the betting odds ${ }^{14}$.

\section{References}

Buraimo B, Peel D, Simmons R (2016) On the positive expected utility of combination wagers. Decision Analysis. 13(3): 209-212.

D’Astous A, Di Gaspero M. (2015) Heuristic and Analytic Processing in Online Sports Betting. Journal of Gambling Studies. 31: 455-70.

${ }^{13} \mathrm{We}$ also note that more complicated wagering strategies are in principle feasible for risk-averse individuals combining both win and place bets as well as win or place bets on other horses in the same race. (See e.g.Buraimo et al (2016), Peel (2017)). However optimal solutions for these wagering strategies are extremely complicated and do not have closed form solutions.

${ }^{14} \mathrm{McCullagh}$ (2005) notes that the use of analgesics in the treatment of persistent vegetable state represents an each-way bet. 
Fees E, Müllera H, Schumacher C (2016) Estimating risk preferences of bettors with different bet sizes. European Journal of Operational Research. 249 (3): 1102-1112.

Gainsbury S M, Russell A J (2015) Betting Patterns for Sports and Races: A Longitudinal Analysis of Online Wagering in Australia. Journal of Gambling Studies. 31: 17-32.

Golec J, Tamarkin M (1998) Bettors Love Skewness, Not Risk, at the Horse Track.

Journal of Political Economy. 106(1): pp. 205-225.

Harrison G.W, Swarthout J.T (2016) Cumulative Prospect Theory in the Laboratory: Reconsideration. WP (CEAR) at Georgia State University.

Harville D.A. (1973) Assigning probabilities to the outcomes of multi-entry competitions, Journal of the American Statistical Association, 68 (June 973), pp. 312316.

Johnson E.V, Bruce A. C (1998) Risk strategy under task complexity: a multivariate analysis of behaviour in a naturalistic setting. Journal of Behavioral Decision-Making. 11:1-17.

Johnson J.E.V, O’Brian R, Sung M-C, 2010 Assessing Bettors' Ability to Process

Dynamic Information: Policy Implications. Southern Economic Journal. 76(4), 906-931

Jullien B, Salanié B (2000) Estimating Preferences under Risk: The Case of

Racetrack Bettors. Journal of Political Economy. 108(3): 503-530.

Kelly J. L. Jr (1956) A new interpretation of information rate. Bell System Tech.

J. 35: 917-926.

Lessman S, Sung M.C, Johnson J (2009) Identifying winners of competitive events: A SVM-based classification model for horserace prediction. European Journal of Operational Research. 196: 569-577. 
Lo S. Y, Bacon-Shone J (1994) Comparison between two models for predicting ordering probabilities in multi-entry competitions. The Statistician. , 43(2):317-327.

McCullagh P (2005) Conscious in a Vegetative State? A Critique of the PVS Concept. Springer.

Peel D.A. (20170) Wagering on more than one outcome in an event in Cumulative Prospect Theory and Rank Dependent Utility. Economics Letters. 154, issue C, 45-47. Prelec D (1998) The Probability Weighting Function. Econometrica. 66(3): 497-527.

Read D. and Grushka-Cockayne Y. (2011) The similarity heuristic. Journal of Behavioral Decision Making. 24: 23-46.

Quandt, R E (1986), Betting and Equilibrium. Quarterly Journal of Economics. 101. 201-17.

Quiggin J (1982). A Theory of Anticipated Utility. Journal of Economic Behavior and Organization. 3(4): 323-343.

Sauer R.D (1998) The Economics of Wagering Markets. Journal of Economic Literature. 36(4): 2021-2064.

Scholten M, and Read D (2014) Prospect theory and the 'forgotten' fourfold pattern of risk preferences. Journal of Risk and Uncertainty. 48: 67-83.

Sonwberg E, Wolfers J (2010) Explaining the Favorite-Long Shot Bias: Is it Risk-Love or Misperceptions? Journal of Political Economy. 118,. 723-746.

Stern H.S (2008) Estimating the Probabilities of the Outcomes of a Horse Race (Alternatives to the Harville Formulas). Efficiency of Racetrack Betting Markets. Hausch, Lo and Ziemba. pp. 225-235. 
Tversky A, Kahneman D (1992) Advances in Prospect Theory: Cumulative Representation of Uncertainty. Journal of Risk and Uncertainty. 5(4): 297-324.

Weitzman M (1965) Utility Analysis and Group Behavior: An Empirical Study Journal of Political Economy. 73(1): 18-26. 